\title{
Building a Digital Society: \\ Questions for Communication Researchers
}

\author{
Catherine Middleton \\ Ryerson University
}

\begin{abstract}
This paper outlines three areas in which communication researchers can offer insights on the ongoing development of a digital society: infrastructure development, the role of mobile connectivity, and the need for better data through which to understand access to, and engagement in, digital society. The paper offers a discussion of digital society, then outlines a variety of research questions that can be explored to help shape digital society in citizencentric ways. It concludes by noting the value of research as a means of introducing alternative perspectives to discourses about digital society.
\end{abstract}

\section{Some Context}

More than 130 countries are now recognised as having a digital strategy (Cisco and International Telecommunication Union 2013). The scope of such strategies varies widely, ranging from specific short-term programs for investing in broadband infrastructure, like Canada's 2009-2012 Broadband Canada program (Industry Canada 2009), to long-term comprehensive visions for economic transformation through widespread adoption of information and communication infrastructure, as in Singapore where the iN2015 vision (Infocomm Development Authority of Singapore 2010) is supported with government investment in a next generation broadband network (Infocomm Development Authority of Singapore 2013) and initiatives to develop information and communication technology (ICT) skills across the economy.i What is common across strategies is a commitment to advance availability and uptake of digital technologies to enable participation in a digital society.

Governments are also undertaking specific initiatives to transform service delivery. In the United Kingdom, the 'digital by default' approach will deliver "digital services which are so straightforward and convenient that all those who can use digital services will choose to do so, while those who can't are not excluded" (Cabinet Office 2012, p. 5). In the United States, the digital government strategy aims to enable Americans "to access high-quality digital government information and services anywhere, anytime, on any device" (US Department of State 2012, p. 2). 
Australia’s National Digital Economy Strategy notes “In 2013, the use of online services by Australians covers almost every aspect of daily life, from checking tomorrow's weather forecast to preparing a meal, paying bills, arranging a holiday or accessing education or health services from remote locations. Almost every aspect of life can be enhanced through some form of online service delivery. New ideas that apply digital technology to everyday situations emerge almost daily" (Australian Government 2013, p. viii). While the future of this specific digital economy strategy is uncertain following a change of government, there is no doubt that throughout the developed worldii online services will be central to the ways that people interact and engage with community, business and government in the future.

This move to the online economy offers many potential benefits, including development of more innovative services, more efficient and cost effective service provision, and improved convenience. A shift online is not limited to economic activities - increasingly social engagement and community interaction also take place online, for example through email, social networking platforms (to share messages, exchange photos) and online chats (video and text). However, as moving to a digital environment requires use of access technology (typically an Internet connection, accessible through a computer, tablet or mobile phone) and sufficient literacy and confidence to negotiate the online world, there are concerns that this digital transformation may disenfranchise citizens who do not have the capacity for online access.

While governments often frame their efforts in facilitating and encouraging the development of the digital ecosystem as digital economy initiatives, from a citizen perspective, it is a digital society that is of concern. Digital society is being shaped by governments, industry, civil society organisations and individuals, each with somewhat different (and sometimes conflicting) interests and priorities. As the contours of digital society are negotiated among stakeholders, there is a role for communication researchers to investigate and articulate citizens' technological and literacy needs, and to bring these needs to the attention of policy makers, regulators, and infrastructure and service providers. iii The sections below discuss some challenges in connecting to digital networks, identify opportunities for researchers to advance understandings of the infrastructure needs of citizens, and make the case for ongoing research to assess citizens' capacities to engage with society through digital means.

\section{Access to Fixed Line Communications Infrastructure}

As digital platforms become the default for service delivery and communication, there is a need to re-examine the characteristics of broadband networks that provide connectivity to digital services, in order to determine what is required for full participation in the digital society and consider how these requirements can be met. Similar to the emergence of other 
large scale infrastructures (Jackson et al. 2007), broadband networks that provide Internet access have been developed by multiple players, using a variety of technologies, resulting in inconsistent user experiences. When commercial broadband services first became available to households in the late 1990s, Internet access was not essential to daily life, and Internet services were deployed on a best effort' basis. This best effort model still applies to much Internet traffic, meaning that mechanisms are not deployed to guarantee the quality of service of particular transmissions across the Internet, thereby compromising reliability for certain applications and services. Further, as different types of networks have different capacities, there is a need to either design digital services to the lowest common denominator (for instance recognising that many Internet connections have very low capacity to upload data) or accept that those with limited capacity connections will be disadvantaged when services are designed to make effective use of the most advanced connections.

Governments often view the provision of digital connectivity as an exercise in improving the availability of high speed Internet services, and it is common for national broadband plans to define broadband in terms of download speeds only. In failing to recognise broadband connectivity as an enabler of services beyond Internet access and by not establishing requirements for upload capacity, quality of service, and reliability that allow for delivery of a broader range of services, the power of broadband networks as enabling infrastructure is constrained. It is certainly possible to deliver good quality services over the Internet, but models that develop broadband networks to provide uniform, universal connectivity across a population, support a multitude of service providers and allow for service quality guarantees offer a much stronger platform for innovation. However, as evidenced by the many challenges in building such a national broadband infrastructure in Australia, there is much to be learned about how to develop a compelling business case for such an approach, to convince the public of its value, and to manage the complexities of building broadband infrastructure on a national scale.

Much broadband infrastructure has been developed and is controlled by the private sector. While private ownership of infrastructure is not inherently bad, there are times when Internet service providers' commercial practices may constrain individuals' abilities to use their Internet services in ways that they want. As the Internet becomes more essential to everyday life, constraints in its use become more problematic, especially as individuals often have limited choice in service providers. It is important to understand the impacts of these constraints (examples of which are noted below), for those developing digital services, and for everyone using the Internet in their daily activities. 
If the Internet is indeed an essential infrastructure, should principles of neutrality and nondiscrimination apply to services and content available over the Internet? The principle of network neutrality is important in ensuring that Internet subscribers can access content from any source without the need for content providers to negotiate preferential treatment to ensure their content is available. In other words, network neutrality requires that Internet service providers (ISPs) allow traffic to flow over their networks without unreasonable discrimination as to its source, making it possible for anyone to communicate with or deliver services to anyone else. At the time of writing, network neutrality rules are under review in the US, iv and the CRTC (Canada's telecommunications and broadcasting regulator) is investigating a complaint that Canadian mobile ISPs are offering preferential access to their own mobile TV offerings, and disadvantaging their customers when they access competing video services. ${ }^{v}$

Another concern for Internet users arises when a service provider attempts to influence the information content provided to its customers, and to use customer information in ways that violate their privacy rights. A recent case is that of Bell Canada's "Relevant Ads" program, implemented in late 2013 for its mobile Internet subscribers and to be extended to fixed broadband customers at a later date. The program was implemented on an opt-out basis, and allows Bell to use data about customers' online browsing, location, television viewing and phone calling patterns to provide 'more relevant' advertising to its customers. However, as an Internet service provider, there is an expectation that customers have simply signed up for an Internet service, allowing them to select the content and services they choose, without any additional content (relevant or not) being imposed upon them by the service provider.

A formal complaint to the CRTC by the Public Interest Advocacy Centre and the Consumers' Association of Canadavi argues that changing this relationship violates the Canadian Telecommunications Act. The program has also sparked an investigation by Canada's Privacy Commissioner as data on users' online behaviours are being tracked by the Internet service provider without user consent (opting out only impacts the advertisements served to users, it does not exclude customers from behaviour tracking). As society becomes increasingly reliant upon Internet service providers to provide connectivity to the services essential to daily life, it is important to raise awareness of instances where service providers exploit their customers for commercial gain, or violate customers' reasonable expectations of privacy in transacting their lives online.

Getting services fixed when something goes wrong often proves challenging. Years ago, going without Internet service for a couple of days would not cause great difficulty for most, but now, in an increasingly 'digital by default' world, a problem with service means that people are disconnected from the infrastructure required to access essential services. The onus of 
resolving the problem is firmly on the consumer, and often great resilience is needed to fully resolve complaints to the consumers' satisfaction. Research by the UK Communications Consumer Panel found "some consumers are suffering in silence while for others, the negative experience of contacting their provider - the time taken to resolve a complaint, the number of contacts required and the sheer level of persistence demanded to reach a solution - made the whole situation worse," concluding that "this is simply unacceptable."vii

In an ideal world, individuals would have an extensive choice of Internet service and broadband network providers, allowing them to avoid those with unfavourable terms of service. Some countries have been more successful than others in establishing strong competition among Internet service providers. There are also instances where communities or governments have decided to build their own infrastructure, providing an opportunity for alternative approaches to Internet service provision, often on more favourable terms. For most individuals however, a do-it-yourself approach to infrastructure is highly impractical, and in some locations in the United States, local initiatives to develop infrastructure that would compete with private sector providers are banned or constrained. viii

The discussion above notes a number of issues that impact individuals' access to Internet services. As Internet access is essential in a digital society, there is a role for researchers to articulate these access challenges, and to identify approaches to improving access. Efforts to define what adequate Internet service consists of when it is the platform underpinning service delivery and communication are necessary. Researchers can explore the deficiencies in service availability and identify policy actions that can help to ensure that adequate Internet infrastructure is available to all citizens at an affordable price. There are opportunities to explore alternative models of network provision, focusing on identifying various stakeholders' needs and finding ways to satisfy them. Particular challenges persist in providing service to rural and remote areas where existing coverage and choice of providers is poor. There are questions about the role of regulation, for instance to ensure network neutrality principles are applied. Is more oversight needed to ensure that citizens get the services they pay for, and that problems in service delivery are resolved in a way that recognises the essential nature of connectivity in a digital society? If so, what form(s) might such oversight take?

\section{Putting Mobile Connectivity on the Policy Agenda}

In 2011, the Australian Communications and Media Authority observed: "There is widespread recognition that mobile broadband services are an economic enabler within society and the provision of these services, technologies and applications in the wider community is in the public interest" (Australian Communications and Media Authority 
2011). The International Telecommunication Union estimates there are now more than 2 billion mobile broadband subscriptions worldwide (International Telecommunication Union 2013b), and Cisco forecasts increasing demand for additional services over the next few years (Cisco 2014). Although demand is strong for mobile services, mobile broadband access is much more expensive than fixed line access at present. Despite the convenience of anytime, anywhere access to the Internet when connecting with mobile broadband, individuals often limit their use when away from a home base, as evidenced by data showing that the vast majority of data is downloaded over a fixed line connection rather than a wireless one (Australian Bureau of Statistics 2013). This behaviour may suggest that although individuals find value in mobile broadband services, the current models for service provision do not fully meet their needs for connectivity while away from their fixed line services.

Provision of mobile broadband services is somewhat fragmented. In addition to the services from commercial providers, represented by the 2 billion subscribers, mobile broadband connectivity is available in many locations through Wi-Fi. There are no comprehensive statistics that track Wi-Fi users, and data downloads on Wi-Fi devices are recorded as fixed line downloads, making it difficult to determine the demand for, and use of this form of mobile broadband connectivity. Service is available on a patchwork basis, with many different providers offering Wi-Fi coverage in specific geographic locations, sometimes for free, sometimes not. Public Wi-Fi connections are often unreliable - some simply do not work at all, and others offer very slow speeds or allow only limited access to particular online sites and services.

At present, mobile broadband is often viewed primarily as a complement to fixed line services. Policies tend to focus on shaping the environment for commercial mobile broadband provision (e.g. licensing and allocating spectrum). To better reflect user experience, it is suggested that mobile broadband should be defined broadly as a service offering wireless broadband connectivity, accessible over licensed or license-exempt spectrum (i.e. from commercial or non-commercial providers, through Wi-Fi or through commercial providers' networks) and available in multiple locations. ${ }^{\text {ix }}$ Existing business models offer mobile broadband connectivity in silos, with commercial services not integrated with Wi-Fi offerings. This approach can be frustrating for consumers who want reliable, affordable coverage without constantly having to negotiate the terms of access to available services.

There are policy questions as to whether mobile access to the Internet is necessary to enable full engagement in a digital society. Should efforts to develop robust broadband infrastructures expand to include mobile connectivity? Is it reasonable for citizens to expect access to the Internet from everywhere, and if so, should making broadband coverage 
ubiquitous be an objective for governments? What are the characteristics of good mobile broadband connectivity, in an era of digital by default services? What do consumer-centric business models for mobile broadband connectivity look like, and how do they differ from existing offerings? What policy options are there to encourage extension of mobile broadband services, and how can government intervention avoid interference in existing competitive markets? To date, national government efforts have focused on defining the type of fixed broadband infrastructure required to enable a digital society, with accompanying actions to foster fixed line infrastructure development where needed. But as the OECD asks, “Why shouldn't every fixed network node support a mobile wireless connection?" (EECD 2012). This is as much a political question as a technical one, but raises further questions about the role of policy to extend mobile broadband coverage through Wi-Fi as well as commercial services. These are some of the many questions to be investigated regarding the ongoing role for mobile broadband in a digital society.

\section{Data for a digital society}

Ensuring good access to the Internet and other broadband services is essential in a digital society. It is important to be able to monitor the provision of broadband services, to assess coverage, as well as quality, reliability, and affordability, so as to understand whether this essential digital infrastructure is meeting citizens' connectivity needs. Connectivity provides a platform for engagement but to actually make use of online services, and to interact with others in a digital environment, individuals need to know how things work. The concept of digital literacy is used to describe an individual's ability to use the Internet and online tools and services effectively. Initiatives to improve digital literacy across populations are central to many national digital strategies, and it is essential to be able to understand literacy levels when designing new services and encouraging a shift to digital by default engagement with governments and others.

There is extensive research on the digital divide, identifying and describing those who, by choice, economic circumstance or because of a lack of skills, do not make use of digital tools and services, but much more insight is needed to understand the consequences of not engaging in a digital society. The idea of engagement itself is nuanced, and has not been captured effectively in quantitative data compiled by the International Telecommunication Union on the characteristics of an information society (International Telecommunication Union 2013a; Middleton 2013b). Even basic statistics, like Internet adoption rates, are not very informative, because they are based on binary measures, meaning that a highly competent, frequent user is counted in the same way as a tentative, infrequent user. National level surveys offer some additional information, including lists of things that Internet users do online, but still provide limited insights into whether Internet users have the necessary 
skills to negotiate online information and services, ${ }^{\mathrm{x}}$ and to use online tools as a central means of communication. In an increasingly 'always-on' culture, measures like hours spent online are poor indicators of engagement.

Data on connection speeds and costs of fixed and mobile broadband services can be quite contentious. The OECD has been tracking these for years, ${ }^{\mathrm{xi}}$ providing relative rankings of service quality and pricing across countries, and demonstrating changes over time. These data are used by policy makers to demonstrate the success of their policies, or as a call for action when performance is not internationally competitive. Researchers often point to these data to note failures in policy environments, but can be subject to aggressive attempts by service providers to argue that the data are inaccurate, and produced using flawed methodologies. xii Researchers and service providers may choose to be selective in the data they present, focusing on figures that support their particular viewpoints while ignoring others that offer contradictory perspectives. Part of the challenge of making sense of OECD data is that the metrics offered do not always accurately capture the ways that services are used or marketed (e.g. the bundles of services included in price calculations are not reflective of bundles users are offered or would choose to consume, and speed data tracks advertised speeds rather than comparing the speeds tiers users are paying for with what is actually being delivered).

There are opportunities for researchers to engage in policy making processes, for instance by participating in consultations with assessments of the nature of existing infrastructure, or providing data on literacy and engagement in digital society. However, as researchers and policy makers often frame issues in different ways there is work to be done by researchers to better understand how to intervene effectively. xiii But because researchers may frame issues differently, they can offer new perspectives on existing data, and help to identify the sorts of data that, if collected by regulators and government agencies, could allow for better decision making around infrastructure and access in a digital society.

There is a long tradition of research as to how people make use of digital communication technologies, and how networks are provisioned. What is important now is to revisit previous research with a view to understanding what changes when digital technologies are no longer just an additional way of engaging, but are the primary means of interaction for every day activities. What changes when digital technologies are not optional, but essential, and what metrics are needed to assess the changes? Who has the necessary data to understand engagement in a digital society, how could these data be improved, and what partnerships could be developed to foster more informed data analysis? How is essential infrastructure assessed? What does digital engagement really mean, and how can it be recognised? There are many questions that can be better understood with more 
comprehensive, nuanced data, and researchers can partner with policy makers and industry to develop stronger evidence bases for assessment and decision making.

\section{Closing Comments}

In closing, it is noted that researchers can play an important role in informing the development of digital society. This paper has focused on issues related to access to fixed and mobile broadband services, and discussed the need for better data to inform decision making, but it is noted these are not the only avenues for engagement. Regulators and policy makers are influenced by dominant discourses. In matters related to shaping digital society, the viewpoints of industry are well-articulated, but perspectives of civil society stakeholder groups and individual citizens are not always so clear. Alternative perspectives should be articulated, and researchers can use their analytical skills to interpret data and surface perspectives that might otherwise be overlooked.

\section{Acknowledgement}

This paper is based on a keynote address given to the Emerging Issues in Communication Research \& Policy Conference, hosted by the News \& Media Research Centre at the University of Canberra in November 2013.

\section{References}

Australian Bureau of Statistics. 2013. 'Internet Activity, Australia, J une 2013 - Volume of Data Downloaded by Access Connection, for ISPs with More Than 1,000 Subscribers'. Accessed 5 November 2013. Available from: http:// www.abs.gov.au/ausstats/abs@.nsf/mf/8153.0.

Australian Communications and Media Authority. 2011. 'Towards 2020-Future Spectrum Requirements for Mobile Broadband'.

Australian Government. 2013. 'Advancing Australia as a Digital Economy: An Update to the National Digital Economy Strategy'. Canberra: Department of Broadband, Communications and the Digital Economy.

Cabinet Office. 2012. 'Government Digital Strategy'. United Kingdom.

Cisco. 2014. 'Cisco Visual Networking Index: Global Mobile Data Traffic Forecast Update, 2013-2018'.

Cisco; International Telecommunication Union. 2013. 'Planning for Progress: Why National Broadband Plans Matter'. Geneva: International Telecommunication Union.

Industry Canada. 2009. 'Broadband Canada: Connecting Rural Canadians'. Accessed 18 February 2014. Available from: http:// www.ic.gc.ca/ eic/ site/ 719.nsf/ eng/ home.

Infocomm Development Authority of Singapore. 2010. 'Realising The iN2015 Vision. Singapore: An Intelligent Nation, a Global City, Powered by Infocomm'. Singapore: IDA. 
Infocomm Development Authority of Singapore. 2013. 'Fact Sheet: Next Generation Nationwide Broadband Network (J uly 2013)'. Accessed 11 August 2013. Available from: https:// www.ida.gov.sg/ / media/ Files/Infocomm\%20Landscape/ Infrastructure/ Wi red/NextGenNBNFACTSHEET.pdf.

International Telecommunication Union. 2013a. 'Measuring the Information Society'. Geneva: International Telecommunication Union.

International Telecommunication Union. 2013b. 'The World in 2013: ICT Facts and Figures'. Geneva: International Telecommunication Union.

J ackson, Steven J .; Edwards, Paul N.; Bowker, Geoffrey C.; Knobel, Cory P. 2007. 'Understanding Infrastructure: History, Heuristics and Cyberinfrastructure Policy'. First Monday 12 (6-4). http:// dx.doi.org/ 10.5210/ fm.v12i6.1904

Middleton, Catherine. 2013a. 'What About Wireless? An Investigation of Mobile Broadband in Fibre to the Home Environments'. Telecommunications Policy Research Conference; Arlington, VA.

Middleton, Catherine. 2013b. Beyond Broadband Access: What Do We Need to Measure, and How Do We Measure It? In Beyond Broadband: Developing Data-Based Information Policy Strategies, edited by Taylor, Richard D and Schejter, Amit M. New York: Fordham University Press. 9-22.

OECD. 2012. 'Fixed and Mobile Networks: Substitution, Complementarity and Convergence, OECD Digital Economy Papers, No. 206'. Paris: OECD Publishing.

OECD. 2013. OECD Skills Outlook 2013: First Results from the Survey of Adult Skills. OECD Publishing.

Shepherd, Tamara; Taylor, Gregory; Middleton, Catherine. 2014. 'A Tale of Two Regulators: Telecom Policy Participation in Canada'. J ournal of Information Policy 4: 1-22.

US Department of State. 2012. 'Digital Government: Building a 21st Century Platform to Better Serve the American People'. Washington, DC.

\section{EndNotes}

\footnotetext{
i See the Infocomm Talent Portal, at http:// www.infocommtalent.sg.

ii The Broadband Commission for Digital Development has done extensive work advancing digital society in the developing world (see http://www.broadbandcommission.org) but the scope of this paper is on the developed world.

iii There is extensive existing research in these areas. This paper outlines some ways in which these areas can be advanced through ongoing attention and highlights their importance for strengthening citizens' capacity for engagement in digital society.

iv The US Federal Communication Commission's Open Internet Order was struck down by an appeal court in late 2013. The FCC Chair has indicated that the commission will take action to restore the principles of network neutrality that were set out in the Open Internet rules but at the time of writing no action had been taken.
} 
v See CRTC file 8622-B92-201316646. Part 1 Proceeding - Application requesting fair treatment of Internet services by Bell Mobility, extended to consider the fair treatment of mobile TV services offered by Rogers and Videotron.

vi CRTC file 8665-P8-201400762. Part 1 Proceeding - Application regarding Bell's use of customer information.

vii http:// www.communicationsconsumerpanel.org.uk/news-latest/latest/post/304-going-round-incircles-the-consumer-experience-of-dealing-with-problems-with-communications-services

vii See the Institute for Local Self-Reliance's Community Broadband Networks website at http://muninetworks.org/communitymap for information on the 19 US states which have barriers in place to discourage or disallow local broadband initiatives.

ix This definition and arguments about the need for a more user-centric view of mobile broadband are developed more fully in Middleton (2013a).

$x$ The OECD survey of adult skills (OECD 2013) parses out these differences and reveals that many adults have quite limited capacity to solve problems in technology-rich environments.

xi http:// www.oecd.org/sti/broadband/ oecdbroadbandportal.htm

xii See for example the exchanges between Canadian legal scholar Michael Geist, and employees of TELUS, one of Canada's largest wireless service providers, about whether wireless prices in Canada were competitive. http:// www.michaelgeist.ca/ content/view/ 6906/125/

xiii This challenge is explored by Shepherd, Taylor and Middleton (2014).

Cite this article as: Middleton, Catherine. 2014. 'Building a Digital Society: Questions for Communication Researchers'. Australian J ournal of Telecommunications and the Digital Economy 2 (1): 27.1-27.11. DOI: http://doi.org/ 10.7790/ajtde.v2n1.27. Available from: http://telsoc.org/journal 